\title{
Effects of a Rho kinase inhibitor on the sequential expression of ICAM-1, HIF-1 $\alpha$, Bcl-2 and caspase-3 in the retina of rats with oxygen-induced retinopathy
}

\author{
HAIYING WANG ${ }^{1}$ and XIAOLONG CHEN ${ }^{2}$ \\ ${ }^{1}$ Department of Ophthalmology, The Fourth People's Hospital of Shenyang, Shenyang, Liaoning 110031; \\ ${ }^{2}$ Department of Ophthalmology, Shengjing Hospital Affiliated to China Medical University, \\ Shenyang, Liaoning 110004, P.R. China
}

Received February 28, 2013; Accepted May 3, 2013

DOI: $10.3892 /$ ijmm.2013.1410

\begin{abstract}
The aim of the present study was to evaluate the effects of blocking the Rho kinase pathway on non-perfused regions and angiogenesis in the retina of rats using a rat model of oxygen-induced retinopathy (OIR) by observing the sequential expression of intercellular adhesion molecule-1 (ICAM-1), hypoxia-inducible factor-1 (HIF-1), B-cell lymphoma/leukemia-2 gene (Bcl-2) and caspase-3 mRNA following the administration of the Rho kinase inhibitor, fasudil (FSD). A total of 240 newborn rats were randomly divided into a normoxia control $(\mathrm{N})$ group, a hyperoxia $(\mathrm{H})$ group and a $\mathrm{H}+\mathrm{FSD}$ (HF) group. The rats were sacrificed, and the eyes were enucleated from postnatal day (P)12 to P21. Samples were prepared for retinal flat mounts, mRNA and protein quantification. On P14, a higher number of circuitous retinal veins was observed in the $\mathrm{H}$ group compared with the HF group. In the HF group, the avascular area was significantly reduced compared with the $\mathrm{H}$ group on $\mathrm{P} 18(\mathrm{P}<0.01)$. In the HF group, the mRNA expression of Bcl-2 was significantly increased on $\mathrm{P} 15$ compared with the $\mathrm{N}$ and $\mathrm{H}$ group $(\mathrm{P}<0.01)$. On $\mathrm{P} 15$ and $\mathrm{P} 17$ in the $\mathrm{H}$ group and on P13 in the HF group, the mRNA expression of ICAM-1 was significantly increased compared with the other groups $(\mathrm{P}<0.05)$. In the $\mathrm{H}$ and $\mathrm{HF}$ group, the expression of HIF-1 $\alpha$ was significantly increased on P12 compared with the $\mathrm{N}$ group $(\mathrm{P}<0.05)$. On P19 and P21, HIF-1 $\alpha$ expression was significantly increased to a maximum level in the HF group compared with the $\mathrm{H}$ and $\mathrm{N}$ group $(\mathrm{P}<0.01)$. In conclusion, these results suggest that FSD inhibits the expression of ICAM-1, assisting in the release of Bcl-2, suppressing
\end{abstract}

Correspondence to: Professor Xiaolong Chen, Department of Ophthalmology, Shengjing Hospital Affiliated to China Medical University, 36 Sanhao Street, Shenyang, Liaoning 110004, P.R. China E-mail: whyqq_2007@163.com

Key words: high oxygen-induced retinopathy, neovascularization, endothelial cells, Rho kinase, fasudil, intercellular adhesion molecules caspase-3. In the HF group, the retinal flat mounts revealed that FSD had a vasorelaxant effect. On P18, a double-layered retinal vascular network was formed, and the number of non-perfused regions was significantly reduced. However, the late-phase peak expression of HIF-1 $\alpha$ resulted in an inevitable increase in vascular endothelial growth factor expression and further accelerated neovascularization and vascular reconstruction in the immature retinal model.

\section{Introduction}

The incidence of retinal neovascular diseases, including diabetic retinopathy, retinopathy of prematurity (ROP), and age-related macular degeneration (1), has significantly increased in recent years and is one of the major causes of blindness in China. ROP is one of the leading causes of premature blindness in infants. In the oxygen-induced retinopathy (OIR) model frequently used in retinal neovascular research, retinal vessel constriction is induced by high oxygen, resulting in retinal ischemia and hypoxia. Due to immaturity, the contraction of the retinal vascular smooth muscle in infants is sensitively regulated by oxygen concentration (2). Inhalation of high concentrations of oxygen may induce retinal vessel occlusion. Upon removal of high oxygen conditions, hypoxia stimulates the formation of new blood vessels, abnormal vascular proliferation and expansion. The endothelial cells in these new blood vessels lack normal vascular barrier properties. The absence of vascular integrity results in retinal detachment and neonatal blindness due to the proliferation of new blood vessels (2).

Neovascularization (i.e., angiogenesis) is the physiological process that involves the growth of new blood vessels from existing vessels (3). The non-perfused (NP) region, i.e., the hypoxic-ischemic region, is the site of neovascularization and release of vascular endothelial growth factor (VEGF). Hypoxiainducible factor- $1 \alpha(\mathrm{HIF}-1 \alpha)$ (4) regulates VEGF transcription via signal transduction proteins that in turn enhance neovascularization in the retina. The B-cell lymphoma/leukemia-2 (Bcl-2) gene is an oncogene that inhibits apoptosis $(5,6)$. Caspase-3 degrades poly(ADP-ribose) polymerase (PARP), resulting in inhibition of DNA repair, DNA degradation, and apoptosis. Regulatory mechanisms of retinal apoptosis are 
involved in normal development and reconstruction of the retina under hypoxic-ischemic conditions (7). The neovascularization of endothelial cells, disintegration of the capillary basement membrane and intercellular adhesion have been extensively investigated over the past decade $(8,9)$. Intercellular adhesion adhesion molecule-1 (ICAM-1), also known as CD54, is a member of the immunoglobulin superfamily that includes antibodies and T-cell receptors. ICAM-1 can be induced by interleukin-1 and tumor necrosis factor- $\alpha$ and is expressed in the vascular endothelium, macrophages and lymphocytes. ICAM-1 is a ligand for integrin lymphocyte function-associated antigen-1 (LFA-1) (10). When activated, leukocytes bind to endothelial cells via ICAM-1/LFA-1 and transmigrate into the tissues $(11,12)$. A potential role for ICAM-1 in signal transduction has been suggested based on research involving ICAM-1 in cell-cell adhesion, extravasation and infection. Characterizing the role of ICAM-1 has been a major focus of research over the past number of years.

Rho-associated protein kinases (ROCKs) belong to the AGC (PKA/PKG/PKC) family of serine-threonine kinases (13). ROCKs were identified as the first effectors of Rho in rats. They induce the formation of stress fibers and focal adhesion by phosphorylating myosin light chains. In response to ROCK phosphorylation, actin binds to myosin II and increases the contractility of capillary endothelial cells. As such, ROCKs regulate cell-cell adhesion. The loss of ROCK activity disrupts the integrity of tight junctions in endothelial cells. Active ROCK in endothelial cells interferes with E-cadherin-mediated cell-cell contact by activating actomyosin contractility (14). ROCKs are key regulators in the formation of the epithelial apical junctional complex (AJC) (15-17), which is involved in the collapse of the vascular endothelial barrier and the induction of intercellular adhesion. The AJC determines the polarity of retinal capillary endothelial cells, maintains endothelial tight junctions and ensures the integrity of the blood-ocular barrier. Although ROCKs regulate cytoskeletal structure and form AJC structures, cytoskeletal contraction regulated by the increased expression of ROCK can destroy tight junctions and AJC epithelial cell integrity, promoting the expression of inflammatory factors and intercellular adhesion adhesion.

Fasudil (FSD) is a potent ROCK inhibitor and vasodilator (18). Since its development, FSD has been used to treat cerebral vasospasms, which may result in subarachnoid hemorrhage and lead to cognitive decline in stroke victims. It also is effective for the treatment of pulmonary hypertension (19). In general, ROCK inhibitors are valid treatment options for ischemic cardiovascular and cerebrovascular diseases (20). Over the years, FSD has emerged as a potential therapeutic agent for the treatment of neovascular retinopathy due to its post-ischemic vasorelaxant and neuroprotective effects (21).

There is some controversy as to the application of ROCK inhibitors in the treatment of retinal neovascularization (22). Amano et al reported that ROCK inhibitors regulate the endothelial actin cytoskeleton and the underlying microsystem, thereby determining endothelial cell polarity (15). They suggested that the increased expression of Rho-ROCKs improves the vascular endothelial cell number in diabetic retinal diseases, potentially promoting the development of neovascularization. Alternatively, the use of ROCK inhibitors may decrease neovascularization (15). Another study indicated that ROCK inhibitors promote VEGF-mediated proliferation and the neovascularization of endothelial cells in vitro (24). In the present study, we established a rat model of OIR as previously described (25-28) to determine whether ROCK affects retinal neovascularization and to determine the effects of the ROCK inhibitor, FSD, on the expression of ICAM-1, HIF-1 $\alpha$, Bcl-2 and caspase-3. Using this model, we observed the NP region and retinal blood vessel networks around the optic nerve, examined the mRNA expression of ICAM-1, Bcl-2, caspase- 3 and HIF-1 $\alpha$ in samples from 3 treatment groups at different time points, and assessed the effects of FSD on the NP region and vascularization in the retina of rats with OIR.

\section{Materials and methods}

Animal model of ROP (OIR in vivo). Newborn SpragueDawley rats and their mothers were obtained from the Animal Experimental Center at China Medical University, Shenyang, China. All animal experiments adhered to the Association for Research in Vision and Ophthalmology Statement for the Use of Animals in Ophthalmic and Vision Research. Newborn rats were divided into 3 groups: group 1 [normoxia control $(N) n=6$ ] that was not exposed to hyperoxia; group 2 [hyperoxia $(\mathrm{H})$ only, $\mathrm{n}=6$ ] that was subjected to hyperoxia without treatment; and group $3[\mathrm{H}+\mathrm{FSD}(\mathrm{HF}) \mathrm{n}=6]$ that was subjected to hyperoxia and treated with FSD injection.

We implemented a cyclic oxygen exposure protocol that was modified from previous studies on oxygen-induced retinopathy using rats (25-27). Hyperoxic experiments were conducted in an airtight glass container constructed in our laboratory. The chamber was $40 \times 40 \times 50 \mathrm{~cm}^{3}$ (4.5 l) in volume and equipped with inlet and outlet ports. The inlet port received $100 \%$ medical-grade oxygen. Throughout the entire exposure period, airflow from the outlet was monitored for oxygen content using an oxygen monitor. The interior of the chamber was maintained at room temperature. Cyclic hyperoxic conditions of $80 \%$ oxygen for 1 day followed by $21 \%$ oxygen for 1 day were applied from postnatal day (P)1 to P14. FSD was injected intraperitoneally daily $(15 \mathrm{mg} / \mathrm{kg})$ from P7 to $\mathrm{P} 21$, and intraocularly on $\mathrm{P} 12$, and the rats were sacrificed on P12, P13, P14, P15, P17, P18, P19 and P21.

Experimental reagents. FSD was purchased from Asahi Kasei Pharma Corp. (Tokyo, Japan). Rat ICAM-1, Bcl-2, caspase-3, HIF- $1 \alpha$ and GAPDH primers for reverse transcription (RT)-PCR were synthesized by Takara Bio, Inc. (Shiga, Japan). RT kits, the Finnzymes SYBR Premix Ex Taq qPCR kit and TRIzol reagent were purchased from Takara Bio, Inc. Rabbit anti-rat ICAM-1, caspase-3, HIF-1 $\alpha$ polyclonal antibodies, a streptavidin-biotin complex (SABC) antibody and diaminobenzidine (DAB) were obtained from Wuhan Boster Biological Technology, Ltd. (Wuhan, China).

Retinal flat mounts. The rats were sacrificed on P14 or P18. Following intracardial perfusion with saline, both eyes were excised, injected intraocularly with approximately $5 \mu \mathrm{l}$ of $4 \%$ paraformaldehyde and immersed in $4 \%$ paraformaldehyde at $4^{\circ} \mathrm{C}$. After $24 \mathrm{~h}, 1$ eye was prepared as a retinal flat mount with adenosine diphosphate (ADP) histochemical staining and the other eye was embedded in paraffin. For retinal flat mounts, 
Table I. Sequences of rat GAPDH, caspase-3, Bcl-2, ICAM-1 and HIF-1 $\alpha$ primers used for RT-PCR and mRNA quantification.

\begin{tabular}{lll}
\hline Gene & \multicolumn{1}{c}{ Forward (5'-3') } & \multicolumn{1}{c}{ Reverse $\left(5^{\prime}-3^{\prime}\right)$} \\
\hline GAPDH & GCAAGTTCAACGGCACA & CATTTGATGTTAGCGGGAT \\
Caspase-3 & CAGACAGTGGAACTGACGAT & TTTCAGCATGGCGCAAAGTG \\
Bcl-2 & TGAACCGGCATCTGCACA & CGTCTTCAGAGACAGCCAGGAG \\
ICAM-1 & ACCAGACCCTGGAGATGGAGA & ACCGTGGGCTTCACACTTCA \\
HIF- $\alpha$ & CCAGATTCAAGATCAGCCAGCA & CTGTCCACATCAAAGCAGTACTCA \\
\hline
\end{tabular}

Bcl-2, B-cell lymphoma/leukemia-2 gene; ICAM-1, intercellular adhesion adhesion molecule-1; HIF-1 $\alpha$, hypoxia-inducible factor-1 $\alpha$; RT-PCR, reverse transcription-PCR.

the anterior segment was removed and 4 or 5 radial cuttings were made. The cuttings were rinsed, incubated in ADP and lead nitrate, stained with ammonium sulfide and covered with coverslips. Micrographs (x40 and x100) were obtained using a MetaMorph/Evolution MP5.0/BX51 medical imaging system (Olympus, Tokyo, Japan). The NP area, the whole retina area (WRA) and the NP/WRA ratio (\%) were measured (mean \pm standard deviation).

RNA isolation and real-time PCR. Total RNA was isolated from the tissues using TRIzol reagent. cDNA was synthesized using RNA reverse transcription reagents. The $10 \mu \mathrm{l}$ reaction volume for cDNA synthesis included total RNA $(1.0 \mu \mathrm{l}), 5 \mathrm{X}$ PrimerScript buffer $(2.0 \mu \mathrm{l})$, PrimerScript RT Enzyme Mix I $(0.5 \mu \mathrm{l}), 50 \mu \mathrm{M}$ Oligo(dT) primers $(0.5 \mu \mathrm{l}), 100 \mu \mathrm{M}$ random 6-mers $(0.5 \mu \mathrm{l})$ and RNase-free $\mathrm{dH}_{2} \mathrm{O}(5.5 \mu \mathrm{l})$. For cDNA synthesis, the samples were incubated at $37^{\circ} \mathrm{C}$ for $15 \mathrm{~min}$. The reaction was stopped at $85^{\circ} \mathrm{C}$ for $5 \mathrm{sec}$, and the samples were preserved at $4^{\circ} \mathrm{C}$.

Quantitative PCR amplification was performed in 32-well PCR plates using the primers listed in Table I. The 20- $\mu$ l reaction volume included 2X SYBR Premix Ex Taq $(10 \mu \mathrm{l}), 10 \mu \mathrm{M}$ forward primers $(0.4 \mu \mathrm{l}), 10 \mu \mathrm{M}$ reverse primers $(0.4 \mu \mathrm{l})$, a cDNA template $(2 \mu \mathrm{l})$ and water $(7.2 \mu \mathrm{l})$. The reaction conditions were as follows: pre-denaturation at $95^{\circ} \mathrm{C}$ for $10 \mathrm{sec}$ and PCR amplification for 40 cycles at $95^{\circ} \mathrm{C}$ for $10 \mathrm{sec}$ and $65^{\circ} \mathrm{C}$ for $20 \mathrm{sec}$. The data were analyzed using LightCycler software (Roche Diagnostics, Indianapolis, IN, USA).

Electrophoresis and western blot analysis. Equal amounts of protein $(30 \mu \mathrm{g})$ were loaded onto 6 or $12 \%$ gels for sodium dodecyl sulfate-polyacrylamide gel electrophoresis (SDS-PAGE) following denaturation in 5X SDS gel loading buffer [60 mM Tris-HCl (pH 6.8), 25\% glycerol, 2\% SDS, $14.4 \mathrm{mM} 2$-mercaptoethanol and $0.1 \%$ bromophenol blue] in boiling water for $10 \mathrm{~min}$. Electrophoresed proteins were electrotransferred onto a polyvinylidene difluoride (PVDF) membrane (Millipore, Bedford, MA, USA) at a constant voltage of $10 \mathrm{~V}$ for $30 \mathrm{~min}$. The membranes were washed twice with $1 \mathrm{X}$ Tris-buffered saline (TBS) with $0.1 \%$ Tween-20 (TBST, pH 7.4) and pre-incubated with blocking buffer (5\% non-fat dry milk in TBST) at room temperature for $1 \mathrm{~h}$. The blots were incubated with rabbit anti-rat polyclonal ICAM-1 and $\beta$-actin primary antibodies in $\operatorname{TBST}(1: 1,000)$ at $4^{\circ} \mathrm{C}$ overnight. Following incubation with the primary antibodies, the blots were incubated with horseradish peroxidaseconjugated anti-rabbit secondary antibody $(1: 2,000$; Santa Cruz Biotechnology, Inc., Santa Cruz, CA, USA) at room temperature for $1 \mathrm{~h}$. The PVDF membranes were washed and developed using ECL Plus Western Blotting Detection Reagent (GE Healthcare, Amersham, UK). The band densities were quantified by densitometry (Multi Gauge software; Fuji Photo film, Tokyo, Japan).

Statistical analysis. SPSS 15.0 software was used to conduct the statistical analyses. Data are presented as the means \pm standard deviation. One-way ANOVA and the least significant difference (LSD) were used for group comparisons. The correlation between multiple variables was analyzed with Pearson's correlation test. A P-value $<0.05$ was considered to indicate a statistically significant difference.

\section{Results}

The retinal flat mounts indicated that the posterior poles in the $\mathrm{H}$ (Fig. 1A) and HF groups (Fig. 1B) appeared avascular on $\mathrm{P} 14(\mathrm{t}=2.311, \mathrm{P}=0.237, \mathrm{n}=6)$. The central retinal veins were more circuitous and the vascular walls were less smooth in the $\mathrm{H}$ group (Fig. 1A) compared with the HF group (Fig. 1B). On P18, the avascular areas in the posterior poles were larger in the $\mathrm{H}$ group (Fig. 1C) than the HF group. In the H group, retinal neovascular sprouting was evident and disorganized. By contrast, the avascular areas of the posterior poles in the HF group (Fig. 1D) were almost repaired, and retinal doublelayer vascular networks were indistinct. In the HF group, the NP/WRA ratio (Fig. 1E) was significantly lower than that in the $\mathrm{H}$ group on $\mathrm{P} 18(\mathrm{t}=6.793, \mathrm{P}=0.001, \mathrm{n}=6)$.

In the $\mathrm{N}$ group, the mRNA expression of caspase-3 (Fig. 2) was significantly increased compared with the $\mathrm{H}$ and $\mathrm{HF}$ group on $\mathrm{P} 13, \mathrm{P} 15$ and $\mathrm{P} 17(\mathrm{P}<0.01)$. In the $\mathrm{H}$ group, the mRNA expression of caspase-3 (Fig. 2) was significantly increased to a maximum level on $\mathrm{P} 12$ compared with the HF group $(\mathrm{P}<0.01)$. In the HF group, the mRNA expression of Bcl-2 (Fig. 4) was significantly increased on P15 compared with the $\mathrm{N}$ and $\mathrm{H}$ group $(\mathrm{P}<0.01)$. On $\mathrm{P} 15$ and $\mathrm{P} 17$ in the $\mathrm{H}$ group and on $\mathrm{P} 13$ in the HF group, the mRNA expression of ICAM-1 (Fig. 3) was significantly increased compared with the other groups $(\mathrm{P}<0.05)$. In the $\mathrm{H}$ and HF group, the expression of HIF-1 $\alpha$ 

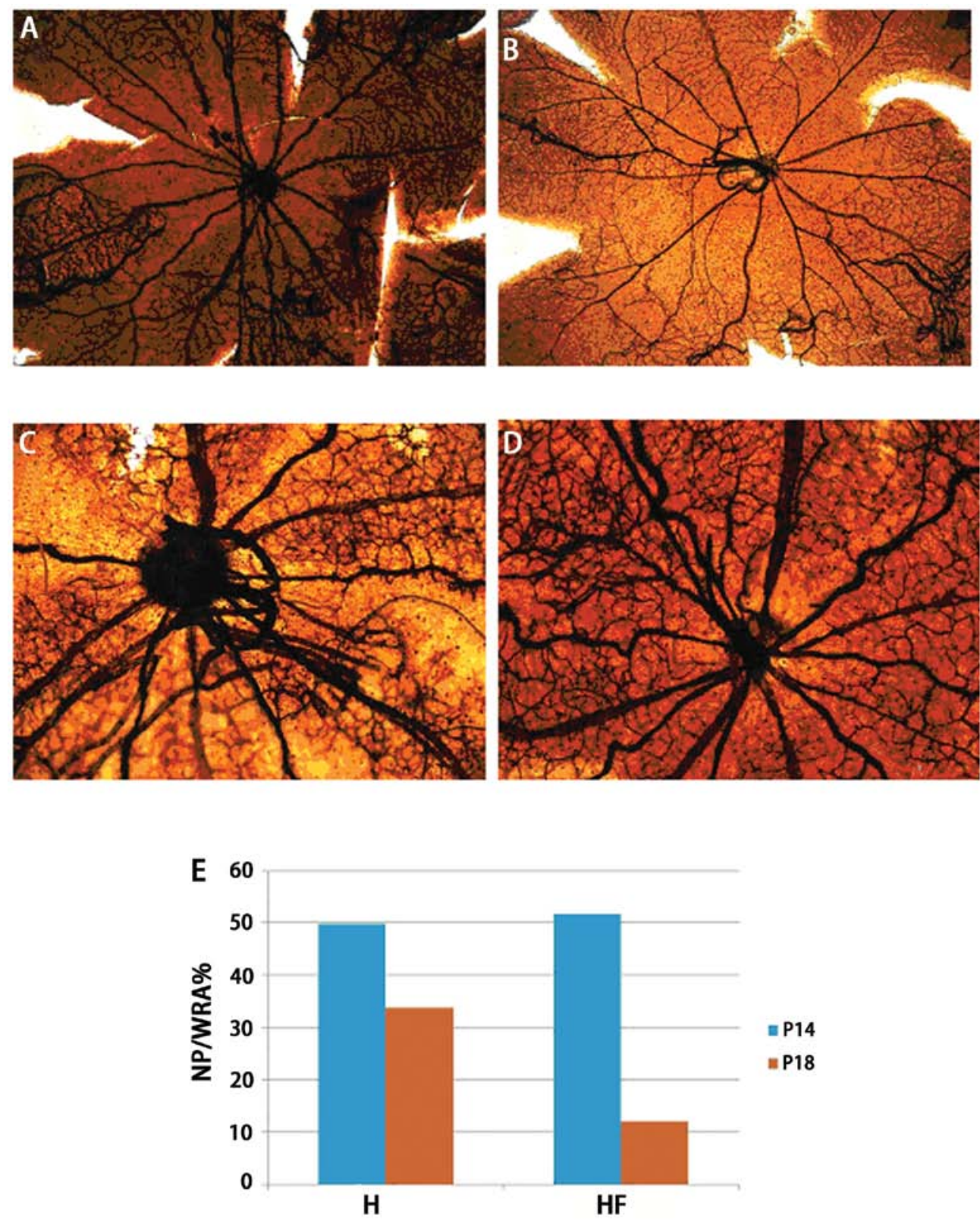

Figure 1. Retinal flat mounts of (A and C) the hyperoxia (H) group and (B and D) the hyperoxia + fasudil (FSD) (HF) group on (A and B) postnatal day (P)14 and (C and D) P18 at magnifications of (A and B) $x 40$ and (C and D) x100. (E) Area ratio comparison of non-perfused (NP) and whole retina area (WRA) in the $\mathrm{H}$ and $\mathrm{HF}$ group.

\section{The expression of Caspase-3 mRNA in the HF, $\mathrm{H}$ and $\mathrm{N}$ groups at different time points}

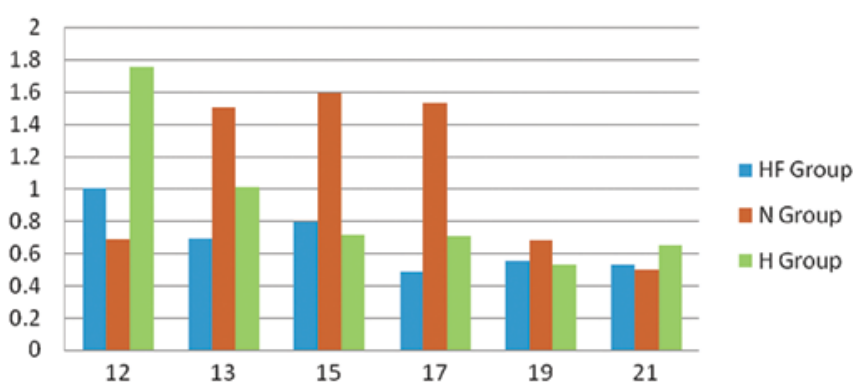

Figure 2. mRNA expression of caspase-3 in the hyperoxia + fasudil (FSD) $(\mathrm{HF})$, hyperoxia $(\mathrm{H})$ and normoxia control $(\mathrm{N})$ groups at different time points (on postnatal days 12,13,15, 17, 19 and 21).
The expression of ICAM-1 mRNA in the HF, H and $\mathrm{N}$ groups at different time points

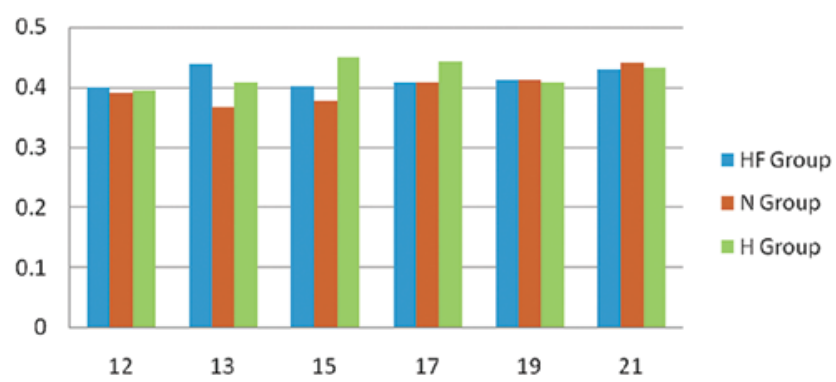

Figure 3. mRNA expression of intercellular adhesion molecule-1 (ICAM-1) in the hyperoxia + fasudil (FSD) (HF), hyperoxia (H) and normoxia control (N) groups at different time-points (on postnatal days 12,13, 15, 17, 19 and 21). 
The expression of $\mathrm{Bcl}-2$ mRNA in the $\mathrm{HF}, \mathrm{H}$ and $\mathrm{N}$ groups at different time points

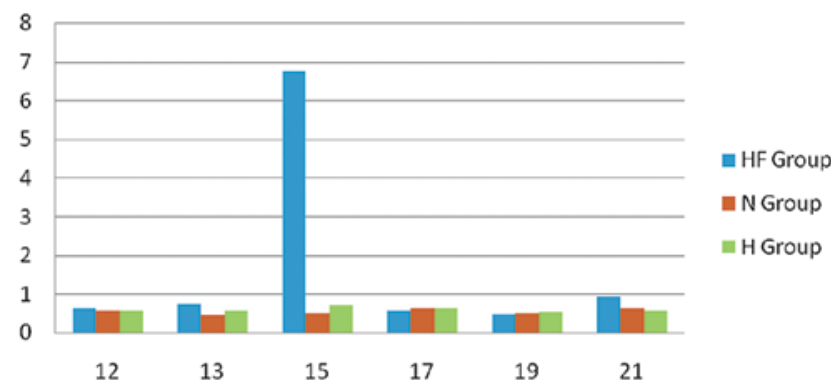

Figure 4. mRNA expression of B-cell lymphoma/leukemia-2 gene (Bcl-2) in the hyperoxia + fasudil (FSD) (HF), hyperoxia (H) and normoxia control (N) groups at different time points (on postnatal days 12,13,15, 17, 19 and 21).

The expression of HIF-1 $\alpha$ mRNA in the HF, $\mathrm{H}$ and $\mathrm{N}$ groups at different time points

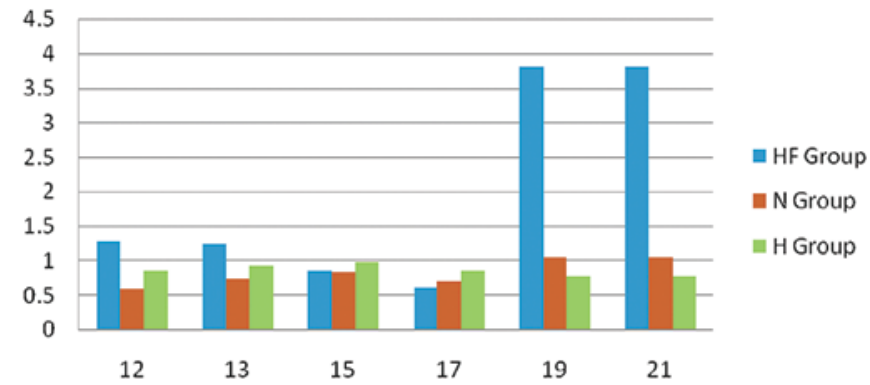

Figure 5. mRNA expression of hypoxia-inducible factor-1 $\alpha$ (HIF-1 $\alpha$ ) in the hyperoxia + fasudil (FSD) (HF), hyperoxia (H) and normoxia control (N) groups at different time points (on postnatal days 12,13,15, 17, 19 and 21).

(Fig. 5) was significantly increased on P12 compared with the $\mathrm{N}$ group $(\mathrm{P}<0.05)$. Of note, HIF-1 $\alpha$ expression was significantly increased to a maximum level on P19 and P21 in the HF group compared with the $\mathrm{H}$ and $\mathrm{N}$ group $(\mathrm{P}<0.01)$.

On P19, western blot analysis indicated that the protein expression of ICAM-1 (Fig. 6) was significantly increased in the $\mathrm{H}$ group compared with the $\mathrm{HF}$ group $(\mathrm{t}=3.768, \mathrm{P}=0.013)$. ICAM-1 expression (Fig. 6) in the $\mathrm{N}$ group was lower compared with the HF group $(\mathrm{t}=-7.357, \mathrm{P}=0.001)$. There was a statistically significant difference in the expression of ICAM-1 between the $\mathrm{H}$ and $\mathrm{N}$ groups (Fig. 6) $(\mathrm{t}=9.022, \mathrm{P}=0.001)$. Western blot analysis on P19 indicated that the protein expression of caspase-3 (Fig. 7) was significantly increased in the HF group compared with the $\mathrm{H}$ group $(\mathrm{t}=4.524, \mathrm{P}=0.011)$. Caspase -3 expression in the $\mathrm{HF}$ and $\mathrm{H}$ group was significantly lower compared with the $\mathrm{N}$ group (Fig. 7) ( $\mathrm{t}=-7.357,-5.688 ; \mathrm{P}=0.002,0.006)$. On $\mathrm{P} 19$, western blot analysis indicated that the protein expression of HIF-1 $\alpha$ (Fig. 8) was significantly increased in the HF group compared with the $\mathrm{H}$ group $(\mathrm{t}=4.524,3.765 ; \mathrm{P}=0.003$, 0.007).

\section{Discussion}

The results of the present study demonstrate the significant effects of FSD on NP areas and retinal neovascularization in rats with OIR. Retinal flat mounts were successfully prepared
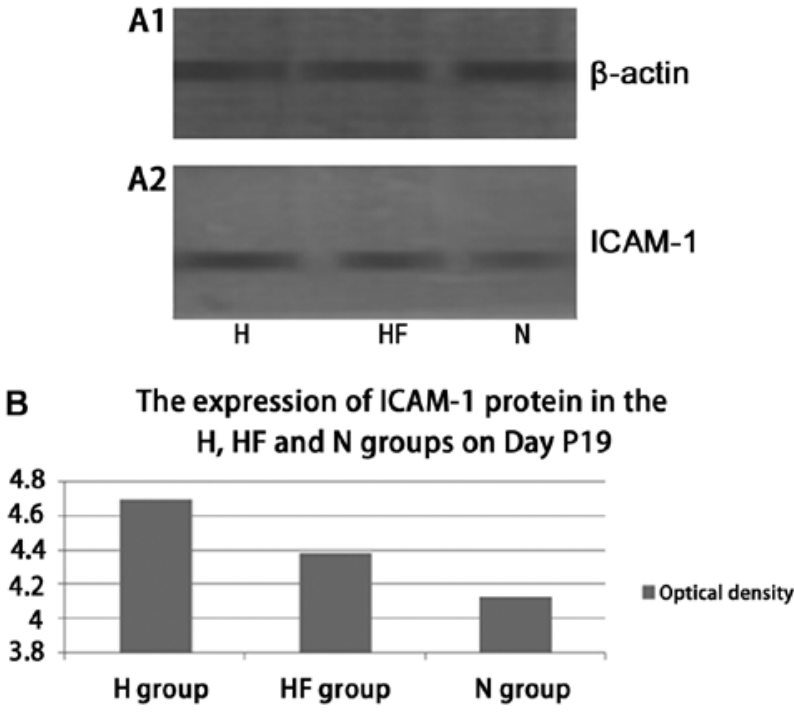

Figure 6. Protein expression of (A1) $\beta$-actin and (A2) intercellular adhesion molecule-1 (ICAM-1) in the hyperoxia $(\mathrm{H})$, hyperoxia + fasudil (FSD) (HF) and normoxia control (N) groups. (B) ICAM-1 optical densities in the 3 groups on postnatal day $(\mathrm{P}) 19$.
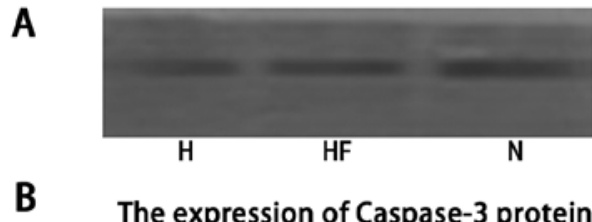

Caspase-3

B

The expression of Caspase- 3 protein in the $\mathrm{H}, \mathrm{HF}$ and $\mathrm{N}$ groups on Day P19

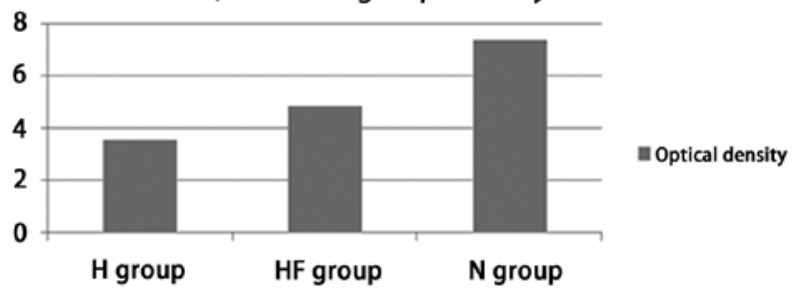

Figure 7. (A) Protein expression of caspase- 3 in the hyperoxia (H), hyperoxia + fasudil (FSD) (HF) and normoxia control (N) groups. (B) Caspase-3 optical densities in the 3 groups on postnatal day (P)19.

A

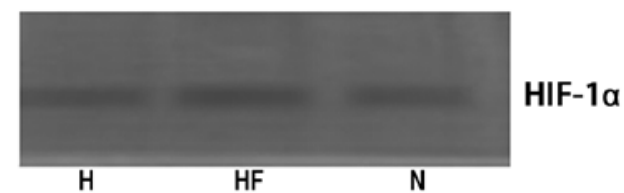

B The expression of HIF-1a protein in the $\mathrm{H}, \mathrm{HF}$ and $\mathrm{N}$ groups on Day P19

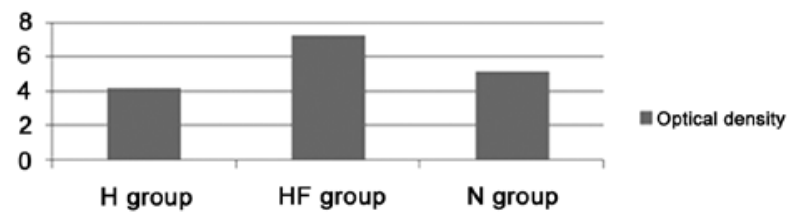

Figure 8. (A) Protein expression of hypoxia-inducible factor-1 $\alpha$ (HIF-1 $\alpha$ ) in the hyperoxia (H), hyperoxia + fasudil (FSD) (HF) and normoxia control (N) groups. (B) Intercellular adhesion molecule-1 (ICAM-1) optical densities in the 3 groups on postnatal day $(\mathrm{P}) 19$. 
before performing immunohistochemistry. The development of retinal NP areas in the OIR model associated with neovascularization damaged the blood-retinal barrier. We observed different microcirculatory alterations in the $\mathrm{H}$ and $\mathrm{HF}$ group on P14 (Fig. 1). Compared with the $\mathrm{H}$ group, retinal vascularization in the HF group was characterized by dilation. On $\mathrm{P} 14$, the NP area and retinal vascularization in the HF group exhibited greater shrinkage and more orderly neovascularization compared with the $\mathrm{H}$ group (Fig. 1). The internal limiting membranes (ILMs) of the animals in the $\mathrm{H}$ group were not integral and a greater number of neovascular endothelial cell nuclei were observed to break through the ILM into the vitreous. In the HF group, the ILM was integral, and more neovascular endothelial cell nuclei were observed under the ILM in the retinal nerve fiber layer. This suggests that the intraocular concentrations of FSD were effective.

On P14, the retinal flat mounts demonstrated significantly less expansion in retinal vascular tortuosity in the $\mathrm{H}$ group compared with the HF group, indicating the expanding effect of FSD on vascular spasms. However, a large NP area in both the $\mathrm{H}$ and $\mathrm{HF}$ group was observed in the posterior pole. On P18, the HF group displayed smooth walls in the retinal arteries and veins, and the NP area was significantly reduced compared with the $\mathrm{H}$ group.

These results suggest that FSD directly inhibits cytoskeletal contraction (15), protects the integrity of tight junctions in vascular endothelial cells, inhibits ICAM-1 transcription and translation, and regulates the distribution and aggregation of ICAM-1. In turn, these activities inhibit leukocyte adhesion in endothelial cells and control retinal inflammation and edema at the posterior pole. The results from the present study confirmed that ICAM-1 mRNA (Fig. 3) and protein expression (Fig. 6) in the HF group were significantly reduced compared with the $\mathrm{H}$ group on P17 in vivo. The RT-PCR and western blot analysis results were concordant with our retinal flat mount findings. In the OIR model, FSD protected endothelial cell tight junctions in the retinal vasculature and promoted the progressive formation of new vascular networks in the surface layers of the retinal nerve fibers.

In mRNA quantification, the expression of caspase-3 (Fig. 2) in the $\mathrm{N}$ group peaked from P13 to P17, indicating possible apoptosis during normal retinal development (6). The expression of caspase- 3 in the $\mathrm{H}$ group increased until P12 and then decreased, which suggests that apoptosis occurred due to retinal vascular contraction under hypoxic conditions. The expression of caspase- 3 in the HF group on P12 was significantly decreased compared with the $\mathrm{H}$ group, indicating the inhibitory effect of FSD on caspase-3 expression. The mRNA expression of Bcl-2 (Fig. 4) in the HF group peaked on P15 and its expression levels were higher or the same compared with the other 2 groups on the other days. The possible effects of apoptosis due to hypoxia and apoptosis during normal development require further investigation. This study demonstrates that FSD has an inhibitory effect on caspase-3 expression and a stimulatory effect on Bcl-2 expression, thereby inhibiting retinal apoptosis in the rat model of OIR.

The mRNA expression of HIF-1 $\alpha$ (Fig. 5) in the HF group was slightly higher than that in the $\mathrm{N}$ and $\mathrm{H}$ group on $\mathrm{P} 12$, followed by a stable decline on P15 and P17, which is consistent with the western blot analysis results (Fig. 8). The expression of
HIF-1 $\alpha$ in the HF group peaked on P19 and P21; on these days its expression was markedly higher compared with in the $\mathrm{H}$ and $\mathrm{N}$ group. The increase in HIF-1 $\alpha$ expression may be associated with the repair of tissue damage induced by hypoxia (28). FSD stimulated the repair process and had a positive effect on nerve protection. However, the increase in HIF-1 $\alpha$ expression led to an increase in VEGF expression, which further induced retinal neovascularization and the possible development of proliferative retinopathy. In the stretched preparation of the retina, reconstruction of the doubled-layered retinal blood vessels in the HF group was observed on P18, suggesting that reconstruction of the compensatory retinal circulatory system was possible following exposure to FSD during development, but that long-term efficacy requires further confirmation.

In conclusion, in our OIR model, FSD protected the nerves in the particularly thin layer of the retinal nervous system. Specifically, FSD inhibited caspase-3 and enhanced Bcl-2 expression, which prevented retinal apoptosis, suppressed ICAM-1 expression, reduced inflammation and improved retinal blood circulation, while maintaining the normal structure of the retina. However, the increase in HIF-1 $\alpha$ expression upregulated VEGF expression. In this model, FSD interfered with the repair of retinal vessels, escalated the contraction of the NP region of the retina, increased the inhibition of apoptosis and reduced inflammation. The reconstruction of neovascularization that was improved by retinal circulation and the accelerated formation of neovascularization requires further evaluation. It is anticipated that the damaging effects of accelerated neovascularization will be dominant over the protective effects in the long-term.

\section{References}

1. Pastor JC, de la Rúa ER and Martín F: Proliferative vitreoretinopathy: risk factors and pathobiology. Prog Retin Eye Res 21: 127-144, 2002.

2. Hartnett ME: The effects of oxygen stresses on the development of features of severe retinopathy of prematurity: knowledge from the 50/10 OIR model. Doc Ophthalmol 120: 25-39, 2010.

3. Penn JS (ed): Retinal and Choroidal Angiogenesis. Springer, Dordrecht, pp119, 2008

4. Näpänkangas U, Lindqvist N, Lindholm D and Hallböök F: Rat retinal ganglion cells upregulate the pro-apoptotic $\mathrm{BH} 3$-only protein Bim after optic nerve transection. Brain Res Mol Brain Res 120: 30-37, 2003.

5. Zhang Z, Qin X, Zhao X, Tong N, Gong Y, Zhang W and Wu X: Valproic acid regulates antioxidant enzymes and prevents ischemia/reperfusion injury in the rat retina. Curr Eye Res 37: 429-437, 2012.

6. Cellerino A, Bähr M and Isenmann S: Apoptosis in the developing visual system. Cell Tissue Res 301: 53-69, 2000.

7. Ozaki H, Yu AY, Della N, Ozaki K, Luna JD, Yamada H, Hackett SF, Okamoto N, Zack DJ, Semenza GL and Campochiaro PA: Hypoxia inducible factor-1alpha is increased in ischemic retina: temporal and spatial correlation with VEGF expression. Invest Ophthalmol Vis Sci 40: 182-189, 1999.

8. Joussen AM, Murata T, Tsujikawa A, Kirchhof B, Bursell SE and Adamis AP: Leukocyte-mediated endothelial cell injury and death in the diabetic retina. Am J Pathol 158: 147-152, 2001.

9. Barouch FC, Miyamoto K, Allport JR, Fujita K, Bursell SE, Aiello LP, Luscinskas FW and Adamis AP: Integrin-mediated neutrophil adhesion and retinal leukostasis in diabetes. Invest Ophthalmol Vis Sci 41: 1153-1158, 2000.

10. Rothlein R, Dustin ML, Marlin SD and Springer TA: A human intercellular adhesion molecule (ICAM-1) distinct from LFA-1. J Immunol 137: 1270-1274, 1986.

11. Samarin S and Nusrat A: Regulation of epithelial apical junctional complex by Rho family GTPases. Front Biosci 14: $1129-1142,2007$. 
12. Smith A, Bracke M, Leitinger B, Porter JC and Hogg N: LFA-1induced $\mathrm{T}$ cell migration on ICAM-1 involves regulation of MLCK-mediated attachment and ROCK-dependent detachment. J Cell Sci 116: 3123-3133, 2003.

13. Leung T, Chen XQ, Manser E and Lim L: The p160 RhoAbinding kinase ROK alpha is a member of a kinase family and is involved in the reorganization of the cytoskeleton. Mol Cell Biol 16: 5313-5327, 1996.

14. Riento K and Ridley AJ: Rocks: multifunctional kinases in cell behaviour. Nat Rev Mol Cell Biol 4: 446-456, 2003.

15. Amano M, Nakayama M and Kaibuchi K: Rho-kinase/ROCK: A key regulator of the cytoskeleton and cell polarity. Cytoskeleton (Hoboken) 67: 545-554, 2010.

16. Warner SJ and Longmore GD: Distinct functions for Rho1 in maintaining adherens junctions and apical tension in remodeling epithelia. J Cell Biol 185: 1111-1125, 2009.

17. Brady DC, Alan JK, Madigan JP, Fanning AS and Cox AD: The transforming Rho family GTPase Wrch-1 disrupts epithelial cell tight junctions and epithelial morphogenesis; Mol Cell Biol 29: 1035-1049, 2009.

18. Olson MF: Applications for ROCK kinase inhibition. Curr Opin Cell Biol 20: 242-248, 2008.

19. Abman SH: Recent advances in the pathogenesis and treatment of persistent pulmonary hypertension of the newborn. Neonatology 91: 283-290, 2007.

20. Budzyn K, Marley PD and Sobey CG: Targeting Rho and Rho-kinase in the treatment of cardiovascular disease. Trends Pharmacol Sci 27: 97-104, 2006.
21. Shimokawa H: Rho-kinase as a novel therapeutic target in treatment of cardiovascular diseases. J Cardiovasc Pharmacol 39: 319-327, 2002

22. Hata Y, Miura M, Nakao S, et al: Antiangiogenic properties of fasudil, a potent Rho-Kinase inhibitor. Jpn J Ophthalmol 52: 16-23, 2008.

23. Bryan BA, Dennstedt E, Mitchell DC, et al: RhoA/ROCK signaling is essential for multiple aspects of VEGF-mediated angiogenesis. FASEB J 24: 3186-3195, 2010.

24. Arita R, Hata Y, Nakao S, et al: Rho kinase inhibition by fasudil ameliorates diabetes-induced microvascular damage. Diabetes 58: 215-226, 2009.

25. Yin L, Morishige K, Takahashi T, et al: Fasudil inhibits vascular endothelial growth factor-induced angiogenesis in vitro and in vivo. Mol Cancer Ther 6: 1517-1125, 2007.

26. Penn JS, Tolman BL and Lowery LA: Variable oxygen exposure causes preretinal neovascularization in the newborn rat. Invest Ophthalmol Vis Sci 34: 576-585, 1993.

27. Kim WT and Suh ES: Retinal protective effects of resveratrol via modulation of nitric oxide synthase on oxygen-induced retinopathy. Korean J Ophthalmol 24: 108-118, 2010.

28. Sharp FR, Ran R, Lu A, et al: Hypoxic preconditioning protects against ischemic brain injury. NeuroRx 1: 26-35, 2004. 